\title{
O uso da renúncia fiscal na área de museus*
}

Janann Joslin Medeiros e Leila Giandoni Ollaik

\section{Introdução}

Examina-se neste artigo o uso da renúncia fiscal, conforme instituída pela Lei Rouanet, na área de museus. Trata-se da Lei Federal de Incentivo à Cultura, $\mathrm{n}^{\circ}$ 8.313/1991, que institui o Programa Nacional de Apoio à Cultura (Pronac) formado por três mecanismos: Fundo Nacional de Cultura (FNC), Incentivo Fiscal (Mecenato) e Fundo de Investimento Cultural e Artístico (Ficart).

O FNC destina recursos a projetos culturais por meio de empréstimos reembolsáveis ou cessão a fundo perdido. O Mecenato viabiliza benefícios fiscais para investidores que apoiam projetos culturais sob a forma de doação ou patrocínio, em que empresas e pessoas físicas podem utilizar a isenção de até 100\% do valor no Imposto de Renda e investir em projetos culturais, divulgando ao mesmo tempo sua imagem institucional e sua marca, o que não deixa de ser renúncia fiscal. E o Fundo de Investimento Cultural e Artístico (Ficart) funcionaria sob a forma de condomínio, mas até meados de 2011 não tinha sido utilizado. 
Assim, o principal destaque da Lei Rouanet tem sido propiciar incentivos fiscais, possibilitando aplicação de parte do Imposto de Renda devido em ações culturais. Aqui se busca investigar como a área de museus se utiliza desta Lei.

\section{Contextualização}

Há um debate acerca da Lei Rouanet que pode ser resumido da seguinte forma: para uns, "implicaria na desresponsabilização do Estado em termos políticos ou simplesmente significa uma 'opção liberal' de ação pública que permitiria aos empresários a decisão final da alocação de recursos" (Silva, Midlej, 2011, p. 17-18). Ou seja, se baseia na crença de que o mercado tem potencial e permite um processo de alocação de recursos de forma eficaz e até equitativa. Enquanto que para outros "apenas o Estado com sua priorização política é capaz de privilegiar a equidade e a democracia cultural" (SILVA, Midlej, 2011, p. 20). Há ainda o entendimento de que o incentivo fiscal aparece "tanto como método de financiamento" quanto como "mecanismo para superação temporária da crise fiscal do Estado" (Silva, Midlej, 2011, p. 20). Este artigo não entra nesse debate, mas tem por objetivo investigar a implementação de museus pelo uso da renúncia fiscal.

O mecanismo de incentivos fiscais da Lei Rouanet, conforme atesta o Ministério da Cultura (MinC), é uma forma de estimular o apoio da iniciativa privada ao setor cultural. O proponente apresenta uma proposta cultural ao MinC e, caso aprovada, é autorizado a captar recursos. Os incentivadores que apoiarem o projeto poderão ter total ou parte do valor desembolsado deduzido do Imposto devido, dentro dos percentuais permitidos pela legislação tributária.
Como atestou o ministro da Cultura do período de 2003 a 2008, Gilberto Gil, a Lei Rouanet representa o dobro do orçamento que o MinC dispõe. O ministro da Cultura do período de 2008 a 2010, Juca Ferreira, atesta que a renúncia "se manteve como a maior fonte para se financiar a cultura" (Silva, Midlej, 2011, p.125). Em relação aos museus, a situação não é diferente. A renúncia fiscal tem maior representatividade financeira no total de investimento do governo federal em museus (Figura 1).

Mas, o que se deve observar para saber como esta renúncia fiscal tem sido utilizada na área de museus? Com base na revisão de literatura referente à implementação de políticas públicas, foi possível identificar vários aspectos a serem observados, que foram agrupados em seis grandes variáveis: incentivos, autonomia, informação, apoio institucional, apoio social, e etapas e tempo necessário para implementação.

Os incentivos existentes, como recursos financeiros e regras institucionais, são extremamente relevantes em uma análise da implementação de uma política pública, pois, conforme os incentivos, há maior possibilidade de atingir os resultados. Assim ressaltam Hood (1986), Huque (2009), Kraft e Furlong (2007), Lane (2005), Peters (2000), Salamon (2002) e Stiglitz (1988).

A autonomia é outra variável relevante (Peters, 2000). Quanto maior a autonomia do implementador, teoricamente maiores as chances de sucesso, pois é possível fazer adaptações ao longo do processo para superar eventuais dificuldades. O que Peters (2000) denomina autonomia é tratado por liberdade em Kraft e Furlong (2007), por autoridade em Hood (1986), e por coercibilidade em Salamon (2002). Também tratam do grau de liberdade, embora dentro da estrutura de incentivos, 


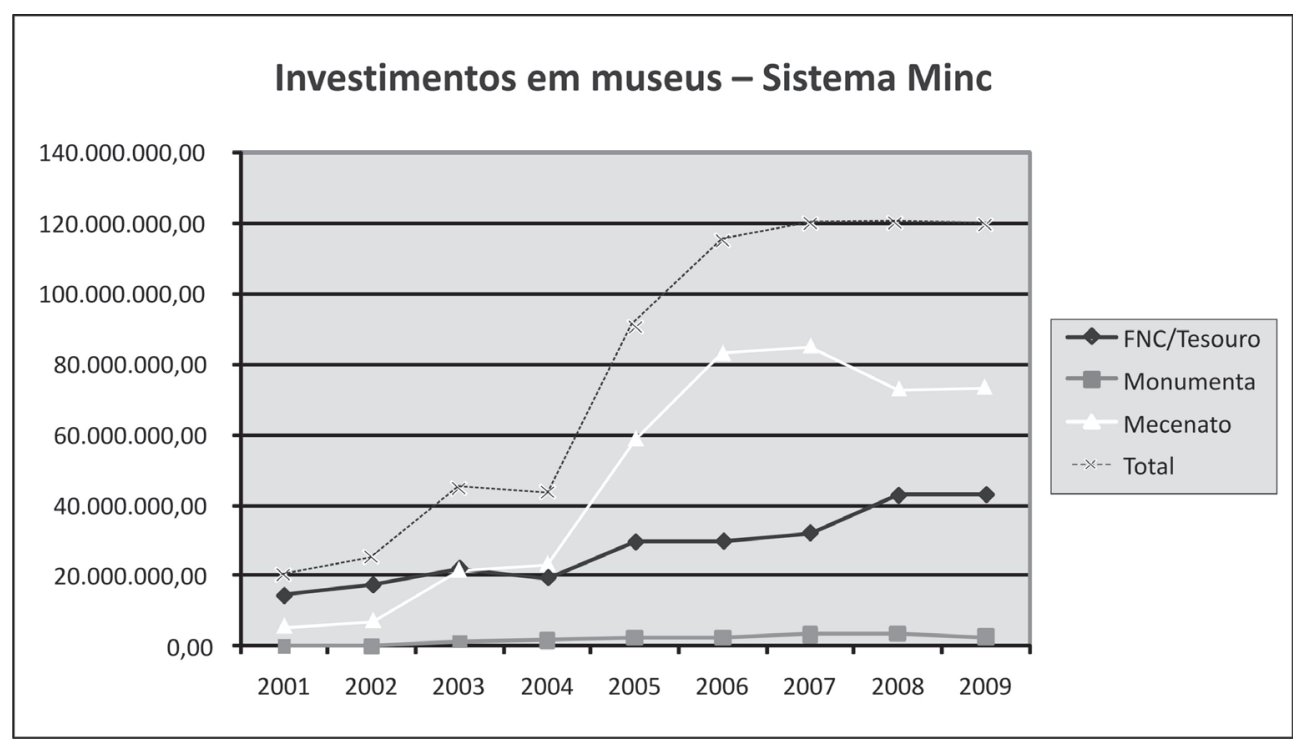

Fonte: Ministério da Cultura (BRASIL, 2010).

\section{Figura 1: Investimentos em museus pelo sistema do Ministério da Cultura}

Stiglitz (1988) e Silva, Jaccoud e Beghin (2005). Esta variável diz respeito ao grau de coerção ou liberdade de cada envolvido no processo de implementação. Há indícios de que quanto maior a autonomia dos gestores, maiores são os incentivos para atingir bons resultados.

As formas e fluxos de transmitir e receber informação também ajudam a compreender o processo de implementação e seus potenciais resultados, como sugerem Hood (1986), Kraft e Furlong (2007), Peters (2000), Salamon (2002) e até mesmo Coase (1937), Stiglitz (1988) e Williamson (2011), quando se referem a custos de transação.

A adequação administrativa, como preconizada por Kraft e Furlong (2007), seria medida pelas etapas e tempo do processo, que também está presente na análise de Pressman e Wildavsky (1973). Este mesmo conceito é tratado por nodalidade em Hood (1986) e por capacidade de realização em Salamon (2002). Se reflete na quantidade de etapas do processo de implementação e ao tempo médio decorrido em cada etapa. Quanto mais etapas e maior o tempo para realização, mais difícil seria a implementação.

A adequação política, mencionada por Kraft e Furlong (2007) e tratada por viabilidade política em Salamon (2002) e Peters (2000), diz respeito ao apoio institucional que haveria para sua implementação, que pode ser por vinculação a prefeituras, governos estaduais, ou mesmo instituições privadas que apoiem o projeto.

$\mathrm{O}$ apoio social seria aqui o apoio da sociedade. Foi citado por Kraft e Furlong (2007) e é tratado por legitimidade em Salamon (2002).

Essas variáveis foram utilizadas para desenvolver a análise, conforme metodologia explicada a seguir.

\section{Metodologia}

Para investigar como a renúncia fiscal tem sido utilizada na área de museus, delimitou-se o período temporal de 2003 a 2010 
no Poder Executivo do governo federal. Essa delimitação deve-se à necessidade de utilizar um período de tempo suficientemente longo para observar e descrever trajetórias (Fox, 1990); mas também recente, para acesso aos dados e melhor compreensão do contexto (YIN, 2003).

Quanto à finalidade, a metodologia foi descritiva e parcialmente analítica, pois se utilizou de oito entrevistas com proponentes da Lei Rouanet a fim de conhecer a percepção dos implementadores "na ponta"1.

Quanto ao caráter das evidências, utilizouse uma mistura de evidências documentais e de entrevistas, conforme descrito no Quadro 1.

Finalmente, quanto às fontes de evidência, a pesquisa foi desenvolvida utilizando dados secundários, extraídos de publicações governamentais, assim como dados primários, levantados mediante entrevistas.

Consultas aos bancos de dados do MinC foram feitas nas classificações da área "patrimônio cultural" e dos segmentos "museu" e "acervo" do SalicNet (sistema do Ministério da Cultura para monitoramento da Lei Rouanet), embora saiba-se que possa haver projetos de museus classificados em outras áreas e segmentos ${ }^{2}$.

Conforme relatório do SalicNet extraído, buscando pelos segmentos "museus" e "acervos", há 262 museus beneficiados pela Lei Rouanet para o período de 2003 a 2010. Desses, 9 são pessoas físicas e 191 são pessoas jurídicas (ou seja, projetos inscritos em nome de museu, instituto, fundação). Das pessoas jurídicas (museus, fundações, centros

\section{Quadro 1: Operacionalização e fontes de evidências das variáveis selecionadas}

\begin{tabular}{|l|l|l|}
\hline \multicolumn{1}{|c|}{ Variáveis } & \multicolumn{1}{|c|}{ Operacionalização } & \multicolumn{1}{c|}{ Fontes de evidências } \\
\hline Incentivos & $\begin{array}{l}\text { Incentivos legais, institucionais, } \\
\text { financeiros }\end{array}$ & $\begin{array}{l}\text { Lei 8.313/91; orçamento, plano plurianual; } \\
\text { relatórios de gestão; } \\
\text { SalicNet, dados do Minc, entrevistas. }\end{array}$ \\
\hline Autoridade & $\begin{array}{l}\text { Forma de gestão, forma de delegação } \\
\text { de autoridade, grau de autonomia do } \\
\text { gestor }\end{array}$ & $\begin{array}{l}\text { Lei 8.313/91; regulamentos; prestações } \\
\text { de contas de alguns museus que } \\
\text { captaram pela Rouanet, entrevistas. }\end{array}$ \\
\hline Informação & $\begin{array}{l}\text { Como é transmitida, se formal ou } \\
\text { informalmente, se de forma } \\
\text { institucionalizada ou não; quais meios } \\
\text { para prestação de contas, problemas } \\
\text { informacionais }\end{array}$ & $\begin{array}{l}\text { Dados do sistema de monitoramento; } \\
\text { análise de prestações de contas, } \\
\text { entrevistas. }\end{array}$ \\
\hline Etapas e tempo & $\begin{array}{l}\text { Quantidade de etapas da } \\
\text { implementação e tempo decorrido da } \\
\text { decisão até o resultado. }\end{array}$ & $\begin{array}{l}\text { Organograma de implementação; } \\
\text { quantidade de etapas; dados do sistema } \\
\text { de monitoramento; tempo entre início e } \\
\text { primeiros resultados, entrevistas. }\end{array}$ \\
\hline Apoio político & $\begin{array}{l}\text { Vinculação a prefeituras ou governos } \\
\text { estaduais; e impacto na gestão do } \\
\text { museu, quando houve mudança do } \\
\text { governante político. }\end{array}$ & $\begin{array}{l}\text { Dados do sistema de monitoramento; } \\
\text { análise de prestações de contas, entrevistas. }\end{array}$ \\
\hline Apoio social & $\begin{array}{l}\text { Forma como o acervo está disponível à } \\
\text { sociedade e uso que a sociedade faz } \\
\text { dele, para aproximação do apoio da } \\
\text { sociedade à política pública em foco. }\end{array}$ & Entrevistas \\
\hline
\end{tabular}

Fonte: Elaboração própria 
culturais, empresas captadoras), várias conseguiram aprovação para diversos projetos ao longo de vários anos (por exemplo, o Instituto Cultural Flávio Gutierrez e a Associação de Amigos da Arte Popular Brasileira, que captaram para diversos projetos, em cada um dos anos analisados). Fazendo a contagem por museu beneficiado, e não por projeto inscrito (já que há museus que inscrevem vários projetos), tem-se 262 museus beneficiados (ou seja, 262 proponentes diferentes).

Desse universo, foram entrevistados oito proponentes (responsáveis pela apresentação, aprovação, captação e implementação do projeto com recursos captados via Lei Rouanet).

O critério para seleção dos oito proponentes entrevistados foi considerar apenas projetos com prestação de contas apresentada ao MinC (há diversos projetos do período 2003-2010 que ainda não apresentaram prestação de contas). Primeiramente, deste universo de projetos, buscou-se contato com todos os proponentes (pessoa física), que eram nove. A escolha de pessoa física foi devido ao fato de ser uma pessoa identificável a responsável pela proposta e pela implementação do projeto. Quando o proponente é pessoa jurídica, são várias as pessoas daquela instituição envolvidas no projeto, havendo inclusive alta rotatividade dentro de cada instituição, ficando mais difícil contatar as pessoas que estiveram de fato envolvidas na implementação. Assim, dos nove que eram pessoa física, foi possível contato com quatro.

Em seguida, buscou-se contatar, por ordem do relatório que nos foi enviado pela Secretaria de Fomento e Incentivo à Cultura (Sefic), os demais proponentes (pessoa jurídica) que implementaram projetos via
Lei Rouanet. Fez-se contato com onze proponentes (pessoa jurídica), mas em sete dessas instituições não sabiam informar quem era responsável pelo projeto à época. Portanto, nessa pesquisa apresenta-se o relato de quatro proponentes (pessoa jurídica), os quais continuam nas respectivas instituições e puderam relatar todo o processo de elaboração do projeto, aprovação, captação e implementação. Poderse-ia ter continuado o contato com tais

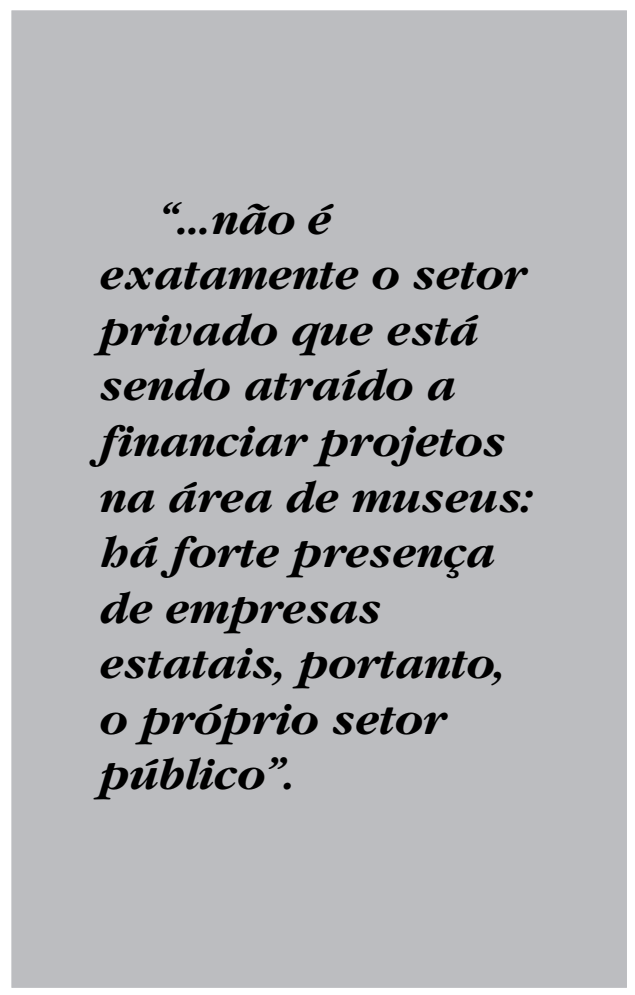

proponentes, mas era claro o ponto de saturação das informações relevantes referentes às seis variáveis em questão (Miles, Huberman, 1994, p. 29-30).

Das oito entrevistas com proponentes quatro com pessoas físicas e quatro com pessoas jurídicas - uma foi feita pessoalmente e sete por telefone, levando em média quarenta minutos cada uma. Essas entrevistas 
foram transcritas, codificadas pelo uso do software NVIVO9, e a análise das codificações contribuiu para os resultados deste artigo.

\section{Resultados e discussão}

A análise dos códigos revela que a variável mais presente nas entrevistas é a relacionada a etapas e tempo, seguida da variável informação. A terceira mais presente é a incentivos, seguida das variáveis apoio institucional, apoio social e autonomia. $\mathrm{Na}$ figura 2, temos um mapa em "árvore" das variáveis, conforme a quantidade de citações para cada variável codificada.

Como resultado da análise dos dados dos museus na Lei Rouanet, temos o que será apresentado a seguir, com base na análise documental e nas entrevistas.

Incentivos: $O$ maior incentivo aos proponentes ao buscarem a Lei Rouanet para implementação de projetos é o recurso público disponível. Afirmam: “O que atrai na Rouanet são os valores". Portanto, a análise foi iniciada pelos valores destinados a museus na Lei
Rouanet. O valor captado pelos museus via Lei Rouanet vinha crescendo de 2003 a 2006, mas teve forte queda em 2007, voltando praticamente ao patamar de 2003, para ao final dar um grande salto em 2010 (Figura 3).

A quantidade de projetos que conseguiu captação também veio crescendo, atingiu seu pico em 2006, mas depois diminuiu um pouco, sem, contudo, voltar ao patamar de 2003; e o aumento no final do período analisado (2010) também não foi tão grande quanto ao aumento financeiro (Figura 4).

A média dos valores captados variou muito, não acompanhando os valores gerais nem os quantitativos (Figura 5).

No entanto, a média não é um dado significativo, pois há forte concentração de recursos em poucos projetos. Os projetos que conseguem captação estão concentrados na região sudeste. E mesmo dentro do universo dos projetos que conseguem captação, há forte concentração de recursos em poucos projetos. Mais da metade dos recursos captados é destinada à apenas dois ou três projetos por ano (Quadro 2).

Nodes compared by number of coding references

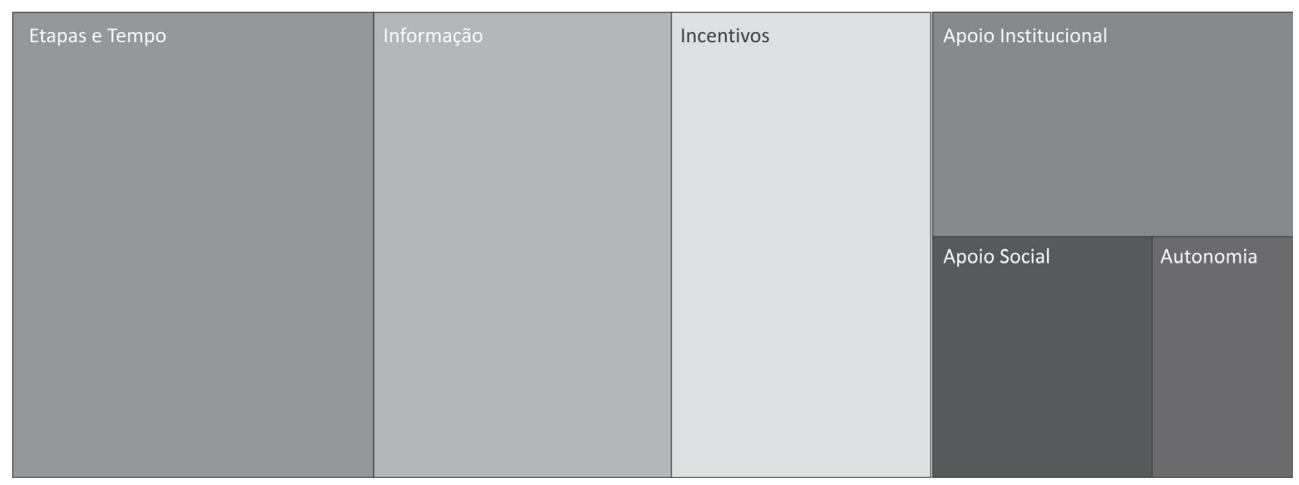

Fonte: elaboração própria utilizando NVIVO9, pela quantidade de citações para cada variável, conforme as oito entrevistas codificadas.

Figura 2: “Mapa em árvore” Renúncia Fiscal 


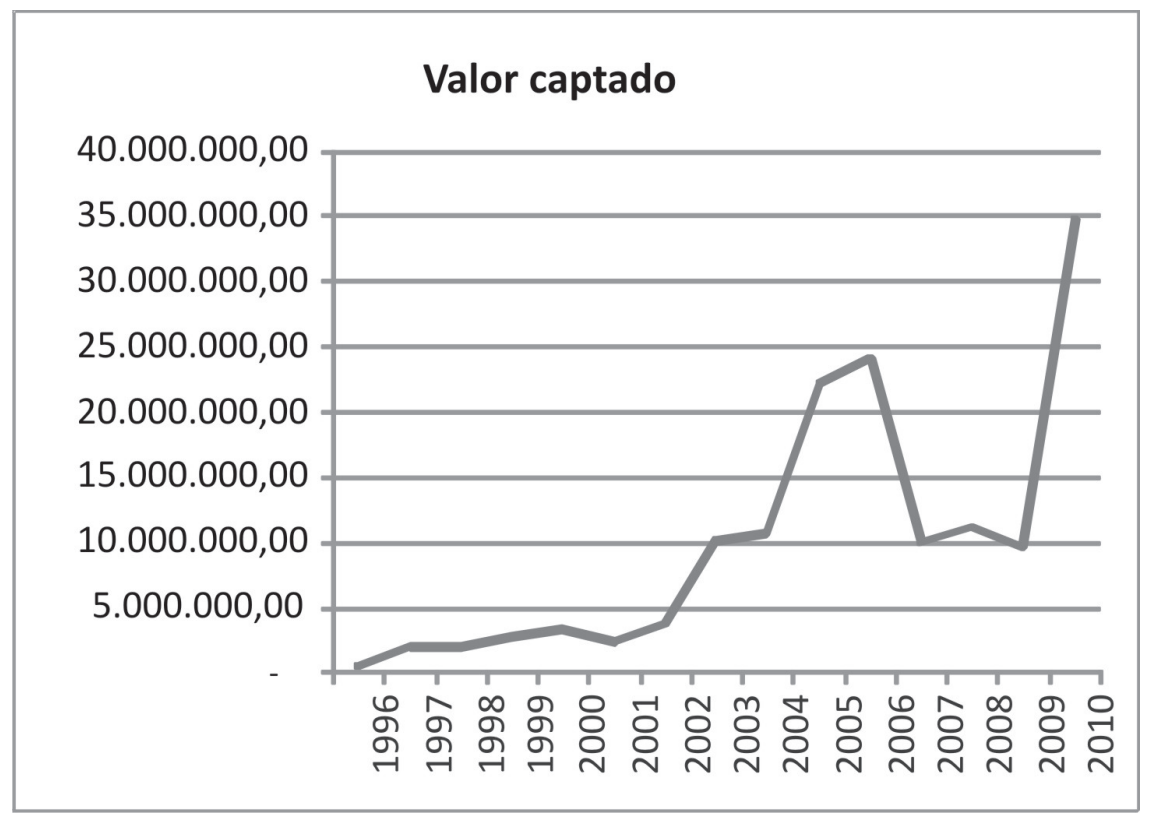

Fonte: SalicNet. Elaboração própria.

Figura 3: Valor total captado pelos museus via Rouanet (1996-2010)

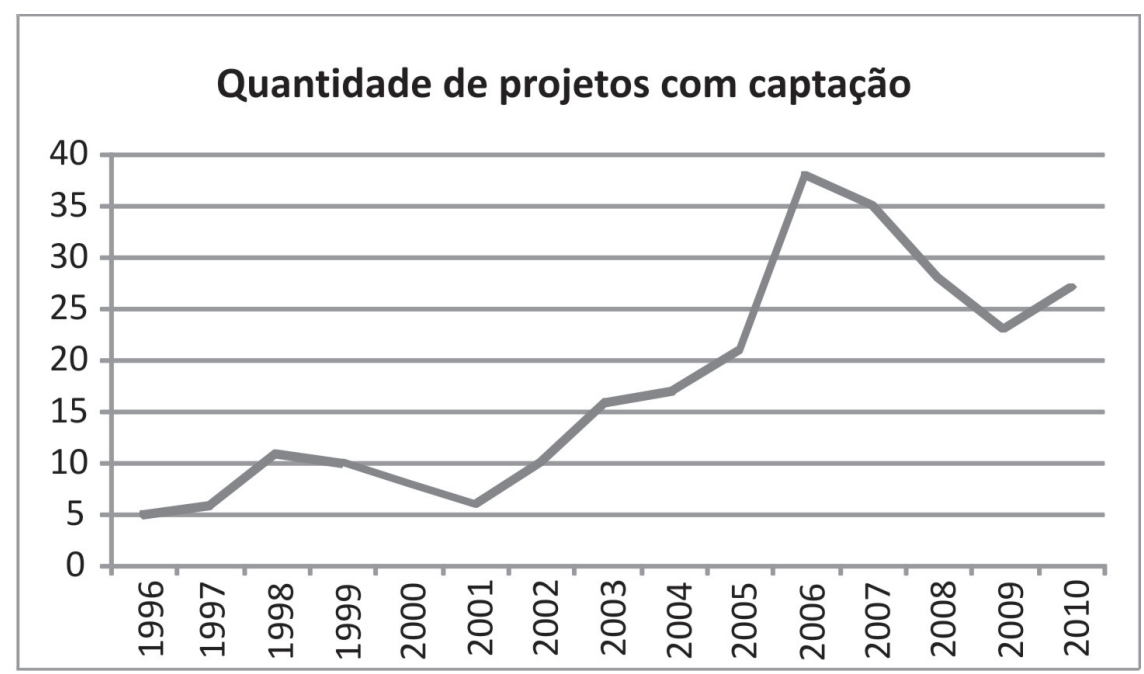

Fonte: SalicNet. Elaboração própria.

Figura 4: Evolução da quantidade de projetos de museus com captação, ano a ano 


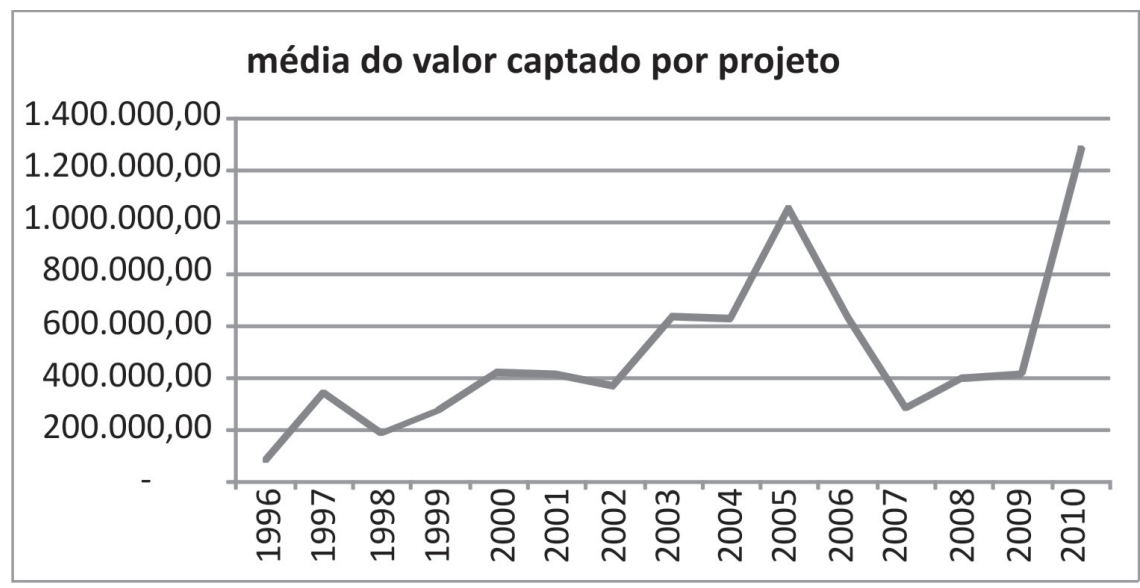

Fonte: SalicNet. Elaboração própria.

Figura 5: Evolução do valor médio captado por museus, por projeto

Quadro 2: Museus com captação pela Rouanet e grau de concentração

\begin{tabular}{|c|c|c|c|}
\hline Ano & $\begin{array}{c}\text { Quantidade de projetos } \\
\text { aprovados que obtiveram } \\
\text { captação }\end{array}$ & Valor captado no ano & Concentração \\
\hline 2003 & 16 & $10.204 .083,67$ & $61 \%$ para dois projetos \\
\hline 2004 & 17 & $10.683 .764,63$ & $53 \%$ para três projetos \\
\hline 2005 & 21 & $22.079 .558,50$ & $54 \%$ para do is projetos \\
\hline 2006 & 38 & $24.016 .470,12$ & $54 \%$ para três projetos \\
\hline 2007 & 35 & $9.987 .318,30$ & $75 \%$ para cinco projetos projetos \\
\hline 2008 & 28 & $11.122 .463,90$ & $50 \%$ para dois projetos \\
\hline 2009 & 23 & $9.504 .644,22$ & $51 \%$ para três projetos \\
\hline 2010 & 27 & $34.626 .867,78$ & \\
\hline
\end{tabular}

Fonte: SalicNet. Elaboração própria.

Em 2003, 61\% dos recursos foram captados por apenas dois projetos. Em 2008, três projetos responderam pela captação de $75 \%$ dos recursos. A forte concentração em poucos projetos se observa em todos os anos do período. Pode-se argumentar que a concentração é decorrência do mecanismo de mercado. Apenas os poucos projetos mais atraentes e com algum apelo comercial conseguiriam captação no setor privado.

Nota-se, no entanto, que não é exatamente o setor privado que está sendo atraído a financiar projetos na área de museus: há forte presença de empresas estatais, portanto, o próprio setor público. Em 2005, 56\% dos valores captados pela Lei Rouanet vieram de empresas estatais (Quadro 3). Em todos os anos a participação das empresas estatais esteve acima de 30\% (exceto em 2010), o que indica que a participação do setor privado no financiamento de museus é ainda menor do que parece ao se examinar os números referentes à Lei Rouanet. A participação das estatais é significativa, tanto em termos de 
valores quanto em termos de quantidade de projetos apoiados. Em 2005, 86\% dos projetos de museus que conseguiram captação via Lei Rouanet, captaram de empresas estatais. Em todos os anos, exceto 2004 e 2010, a participação de estatais ficou acima de 50\%, em termos de quantidade de projetos que conseguiram captação. Nas entrevistas, encontra-se uma percepção disso também³:

- "por ser uma empresa estatal, ela tem uma política de patrocínio diferente, não só de retorno financeiro, mas também de retorno institucional, que muitas vezes (em uma empresa particular) é mais difícil, porque ela tem compromissos imediatos comerciais."

- "uma empresa estatal às vezes pode ter o luxo de não ter esse retorno imediato, ela tem uma preocupação mais institucional, mais fiel à linha de patrocínio." espírito da lei não está sendo atingido. Esse alto índice de participação das empresas estatais não passou despercebido ao Ministério da Cultura (MinC). O ministro Gilberto Gil, embora tenha adotado o slogan "investimentos privados com políticas públicas” (SILVA, Midlej, 2011, p. 119), argumenta que as empresas estatais são, a rigor, entes privados, porque funcionam com a lógica privada, e que foi um grande mérito do ministério ter logrado êxito no esforço de "alinhamento das políticas dessas estatais com as políticas públicas do Ministério” (Silva, Midlej, 2011, p. 122), ressaltando que a presença das estatais tem papel fundamental para o sucesso da política (Silva, Midlej, 2011, p. 127). Chamar empresas estatais de setor privado pode até atender a critérios de direito do ponto de vista de pessoa jurídica, mas não

\section{Quadro 3: Empresas estatais na Lei Rouanet no setor de museus}

\begin{tabular}{|c|c|c|r|r|r|c|c|}
\hline \multicolumn{4}{|l|}{ Museus na Rouanet } & & & \\
\hline $\begin{array}{c}\text { Ano } \\
\text { Valor captado } \\
\text { (A) }\end{array}$ & $\begin{array}{c}\text { Quantidade } \\
\text { de projetos } \\
\text { (B) }\end{array}$ & $\begin{array}{c}\text { média do valor } \\
\text { captado por } \\
\text { projeto (C=A/B) }\end{array}$ & $\begin{array}{c}\text { valor financiado } \\
\text { por estatais (D) }\end{array}$ & $\begin{array}{c}\text { \% do valor captado } \\
\text { que foi financiado } \\
\text { por estatais } \\
\text { (E=D/A) }\end{array}$ & $\begin{array}{c}\text { quantidade de } \\
\text { projetos } \\
\text { fonnciados por } \\
\text { estatais (F) }\end{array}$ & $\begin{array}{c}\% \text { da quantidade de } \\
\text { projetos financiados } \\
\text { por estatais (G=F/B) }\end{array}$ \\
\hline 2003 & $10.204 .083,67$ & 16 & $637.755,23$ & $3.325 .000,00$ & $32,6 \%$ & 9 & $56,3 \%$ \\
\hline 2004 & $10.683 .764,63$ & 17 & $628.456,74$ & $3.840 .342,19$ & $35,9 \%$ & 6 & $35,3 \%$ \\
\hline 2005 & $22.079 .558,50$ & 21 & $1.051 .407,55$ & $12.329 .992,94$ & $55,8 \%$ & 18 & $85,7 \%$ \\
\hline 2006 & $24.016 .470,12$ & 38 & $632.012,37$ & $10.202 .942,29$ & $42,5 \%$ & 30 & $78,9 \%$ \\
\hline 2007 & $9.987 .318,30$ & 35 & $285.351,95$ & $3.251 .629,56$ & $32,6 \%$ & 24 & $68,6 \%$ \\
\hline 2008 & $11.122 .463,90$ & 28 & $397.230,85$ & $3.871 .834,20$ & $34,8 \%$ & 20 & $71,4 \%$ \\
\hline 2009 & $9.504 .644,22$ & 23 & $413.245,40$ & $2.874 .686,56$ & $30,2 \%$ & 16 & $69,6 \%$ \\
\hline 2010 & $34.626 .867,78$ & 27 & $1.282 .476,58$ & $4.056 .606,06$ & $11,7 \%$ & 6 & $22,2 \%$ \\
\hline
\end{tabular}

Fonte: SalicNet. Elaboração própria.

A lógica da Lei Rouanet, inicialmente, era captar recursos do setor privado. As empresas privadas têm isenção do IR, mas essa isenção, teoricamente, não é integral. Assim, algum recurso do setor privado entraria para o financiamento da cultura. Quando o recurso vem de empresa pública, nenhum recurso do setor privado está entrando no financiamento da cultura e o atende ao espírito da lei de incentivo, quanto à captação de recursos diretamente de empresários ou mecenas pertencentes ao setor privado propriamente dito. Além disso, é interessante notar que a presença das estatais é mais fortemente notada se analisamos a quantidade de projetos em vez de seus valores, ou seja, os projetos financiados pelo setor privado se 
apresentam em quantidade menor, mas recebem proporcionalmente mais recursos de cada financiador. Essa análise baseia-se em dados de museus quanto a incentivo fiscal por consulta à SalicNet.

Nota-se que a renúncia fiscal mediante a Lei Rouanet é um mecanismo concentrador, pois, no período de 2003 a 2007, 3\% dos proponentes concentraram 50\% do volume captado. É um mecanismo desigual, pois em 2007 as regiões Sul e Sudeste ficaram com $80 \%$ da verba captada, o CentroOeste ficou com 11\%, o Nordeste com $6 \%$ e ao Norte restou apenas 3\% (BRASIL, 2010). Trata-se de um mecanismo com baixa participação das empresas, pois de cada dez reais captados, apenas um real é dinheiro realmente captado, sendo os outros nove auferidos de renúncia, conforme dados do próprio governo (BrasiL, 2009). Conclui-se que em cada um real (dinheiro) captado, ao menos metade disso é captado do próprio setor público, das empresas estatais. Portanto, do setor privado, capta-se menos de cinquenta centavos para cada dez reais. Em sua concepção, a referida lei ofereceria incentivos para melhor distribuição da oferta de cultura no país. Na prática, nota-se que $80 \%$ dos recursos captados pela Lei Rouanet são para as cidades de São Paulo e Rio de Janeiro, havendo forte concentração.

Da análise das entrevistas, percebe-se que os incentivos são o grande motivador para que proponentes tomem a iniciativa de apresentar projetos:

- "É muito mais difícil conseguir as doações sem esse incentivo fiscal. A Lei Rouanet ajuda muito."

- "Se a pessoa não pode debitar o valor total do imposto, então fica ainda mais difícil de captar."

Alguns procuram aprovar o projeto, para depois buscar captação, e outros concorrem aos recursos e percebem que estar aprovado na Lei Rouanet é exigência do patrocinador:

- "Exige-se que o projeto tenha sido aprovado na Lei Rouanet."

- "Uma das prerrogativas do Petrobrás cultural era que estivesse inserido na Lei Rouanet."

- "Foi um edital da Petrobrás que exigia que o projeto estivesse aprovado na Rouanet."

Outro estímulo são as regras:

- "Entramos na Rouanet também porque não é competitiva. $O$ processo não é competitivo. Você não está concorrendo com ninguém, o mérito do projeto não está em questão. Você simplesmente tem de apresentar um projeto viável e ele é aprovado. Nas leis municipais e estaduais, eu entro em uma competição com outros projetos. $\mathrm{Na}$ Rouanet isso não acontece. O que facilita bem."

- "Nos do governo do estado ou do município é muito mais difícil. O pessoal usa mais lei de incentivo do MinC mesmo. É muito mais fácil do que qualquer outra. A estadual, a fiscal, tem uns requisitos, se você coloca um projeto não pode colocar outro parecido, tem um monte de coisas. O do MinC é muito melhor"

Portanto, os recursos e as regras são os incentivos que movem os proponentes a se inscreverem na Lei Rouanet.

Autonomia: Pode-se investigar a autonomia sob dois pontos de vista: a autonomia referente à seleção dos projetos que serão financiados, e a referente à implementação do projeto.

$\mathrm{Na}$ renúncia fiscal, o governo apenas avaliza os projetos, cabendo às empresas optar por financiá-los, abatendo todo ou parte do montante no Imposto de Renda. A aprovação funciona como maior poder de convencimento junto ao empresário patrocinador (SILVA, 2007a, 2007b). O 
Estado financia, mas quem seleciona é o "mercado". A autoridade está delegada, do governo aos financiadores diretos. Dentro do leque de projetos aprovados, há total autonomia dos financiadores. E mais de $90 \%$ de todos os projetos inscritos são aprovados na Lei Rouanet.

Do ponto de vista do implementador, o grau de autonomia em relação ao governo também é bastante amplo. Pode ser que a autonomia fique restrita a determinações do financiador, mas em relação ao governo é ampla, com restrições mínimas relacionadas à prestação de contas. Todos os proponentes afirmaram que dispunham de total autonomia para implementação, mas nem sempre viam isso como uma qualidade positiva, já que a autonomia total implica também falta de apoio institucional.

Pelas entrevistas, temos:

- "Aí foi tudo aqui, com autonomia".

- "Autonomia total. O gestor do projeto tem sim autonomia total. Eu tenho já liberdade com o detentor do acervo, já de longos anos trabalhando com ele, então eu posso ter bastante autonomia."

- "Eu tive autonomia para implementar um projeto pequeno, muito claro, bem específico".

- "Para contratar gente foi minha própria esposa, que é a especialista nisso, só tem três ou quatro especialistas no Brasil. Nós montamos com os alunos dela, nós montamos a equipe, pegamos uma costureira boa também, é, fizemos. O resto é tudo comprar, comprar móveis, iluminação. Tranquilo. Sem problemas."

- "Fazer, falar, sentar, botar no papel é uma coisa. Executar um projeto sozinho assim... Uma coisa é colocar no papel, a outra é fazer. Não é nada fácil executar um projeto".

- "Não tem complicação nenhuma, é só trabalhar."
- "A gente é quem cuida da manutenção. A ideia é essa mesma. A Rouanet ajuda a iniciar e aí cada um se vira. Dá uma injeção. Criaram um mecanismo. Aí tem de se manter de alguma forma."

- "Se vira aí e apresenta o seu projeto e coloca ele direito, porque a visibilidade está em cima da sua cabeça, é uma espada."

Portanto, pode-se concluir que há alto grau de autonomia quanto ao uso da Lei

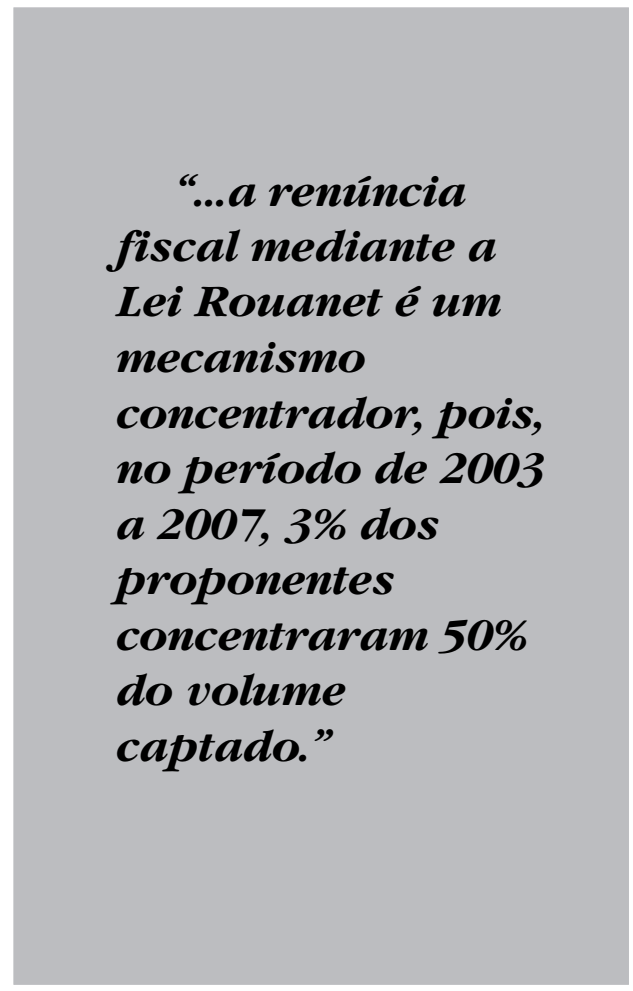

Rouanet por proponentes da área de museus.

Questões Informacionais: A renúncia fiscal é contabilizada na fase de aprovação de projetos. Após o projeto aprovado, no entanto, os proponentes não dispõem de informação sobre onde estão os potenciais financiadores e quais são seus interesses, o que dificulta a captação. Assim, nascem 
"empresas" intermediadoras, que observam quais foram os projetos aprovados via Rouanet e que se oferecem para captar recursos, cobrando uma porcentagem. Esses problemas de informação causam perdas no sistema. A assimetria de informação abre espaço para o oportunismo, como sugere a teoria da agência e a teoria de custos de transação, e cria-se um mercado paralelo para captação.

A Polícia Federal produziu em 2007 e em 2010 relatórios sigilosos sobre projetos da Lei Rouanet. A Operação Mecenas, de 2007, contou com a ajuda da Controladoria-Geral da União (CGU) e da Corregedoria da Polícia Civil do DF. Servidores foram acusados de facilitar a aprovação de certos projetos ou de atrasar a apreciação dos projetos que não aceitavam o esquema de propinas. Estimase que pelo menos $30 \%$ do dinheiro que empresas dizem ter investido em projetos foi devolvido para as próprias empresas de forma ilícita (NoBlat, 2011; MousinHo, 2011).

Segundo a "Operação Mecenas" da Polícia Federal, houve fraude em processos da Comissão Nacional de Incentivo à Cultura (CNIC) a partir de 2004. Integrantes do apoio administrativo do MinC à comissão e produtores culturais supostamente atuavam para facilitar o andamento dos processos, cobrando propina para que os projetos fossem incluídos rapidamente na pauta das reuniões de avaliação da comissão. Além disso, uma servidora da área de avaliação de projetos do Ministério teria ainda o papel de identificar propostas tecnicamente viáveis e repassar as informações aos produtores culturais, que se encarregariam da intermediação. O grupo criminoso cobrava, segundo o delegado da Polícia Federal que conduziu as operações, entre $2 \%$ a $5 \%$ do valor dos projetos (BRASIL,
2008). Embora o caso não envolva a CNIC e o acontecimento tenha ficado limitado a um suposto esquema de dimensões limitadas, expõe dificuldades informacionais.

Outro grave problema informacional é que os montantes de renúncia não são contabilizados no sistema de acompanhamento financeiro governamental (Siafi), dificultando a mensuração do gasto e sua avaliação.

Internamente há problemas informacionais no processo de implementação, no que tange ao monitoramento e ao controle feito pelo Ministério da Cultura. Uma prova disso é a dificuldade de se atestar a informação básica sobre quantos projetos foram aprovados e conseguiram captação. O Quadro 4 mostra essa dificuldade. Se um cidadão acessa o sistema de dados da Lei Rouanet disponível no sítio do MinC (SalicNet), e busca informações relacionadas a museus, obterá uma série de dados. Caso a consulta seja feita mediante acesso ao Relatório de Gestão do Ibram, os dados serão outros, bem mais favoráveis. Também se observará que, caso o cidadão faça uma consulta à Secretaria de Fomento e Incentivo à Cultura (Sefic) - secretaria encarregada da implementação da Lei Rouanet no MinC -, os dados serão ainda outros.

Os dados que constam do Relatório do Ibram (fonte B), e que são mais favoráveis, mostram crescimento da quantidade de museus que captam recursos via Lei Rouanet, mas diferem da consulta direta ao SalicNet e da consulta à Sefic (essas duas são mais similares entre si). Em conversa com o funcionário que elaborou esses dados, que já não trabalha mais no Ibram, foi esclarecido que se chegou a esses números por consulta processo a processo, identificando projetos museológicos em praticamente todas as áreas e segmento ${ }^{4}$. 
Quadro 4: Quantidade de museus que captaram recursos via Lei Rouanet

\begin{tabular}{|c|c|c|c|}
\hline Ano & $\begin{array}{c}\text { Fonte A: } \\
\text { SalicNet Segmento } \\
\text { Museu }\end{array}$ & $\begin{array}{c}\text { Fonte B: } \\
\text { Relatório do Ibram } \\
\text { (BRASIL, 2010) }\end{array}$ & $\begin{array}{c}\text { Fonte C: } \\
\text { SalicNet Segmentos Museu, } \\
\text { Acervos e Acervo } \\
\text { museológico }\end{array}$ \\
\hline 2003 & 16 & 37 & 24 \\
\hline 2004 & 17 & 34 & 40 \\
\hline 2005 & 21 & 89 & 61 \\
\hline 2006 & 38 & 142 & 56 \\
\hline 2007 & 35 & 132 & 34 \\
\hline 2008 & 28 & 146 & 17 \\
\hline 2009 & 23 & 142 & 12 \\
\hline 2010 & 27 & $?$ & 18 \\
\hline
\end{tabular}

Fonte: Elaboração própria. Fonte A: elaboração própria (consulta direta ao SalicNet). Fonte B: elaboração Ibram (não especificam a fonte dos dados publicados). Fonte C: elaboração MinC, mediante consulta deservidores da Secretaria de Fomento e Incentivo à Cultura (Sefic/MinC) ao SalicNet.

Não foi possível confirmar a análise projeto por projeto, pois só quem trabalha no Ministério da Cultura tem acesso à totalidade dos projetos.

A diferença entre o relatório extraído diretamente do sistema SalicNet, (consultando apenas o segmento "museus") e o relatório enviado pela Sefic (que apresentou dados de consulta pelos segmentos "museus", "acervo" e "acervo museológico”) se justifica devido à diferença quanto aos segmentos consultados. No entanto, a diferença deveria ser sempre para maior, já que o relatório que extraímos diretamente do SalicNet foi apenas do segmento "museus", e o relatório da Sefic tratava dos segmentos "museus", "acervo" e "acervo museológico". Essa diferença esperada se observa nos anos de 2003 a 2006, mas curiosamente se inverte nos anos de 2007 a 2010. Supõe-se que isso se deve a falhas no sistema de monitoramento. Informações desencontradas com respeito aos números explicitam problemas informacionais na implementação mediante renúncia fiscal.

Ainda sobre problemas de informação na implementação, detalhando melhor os dados da Sefic/Minc, observamos que apenas seis dos 262 projetos que conseguiram captação de 2003 a 2010 estão em 2011 com sua prestação de contas aprovada. Ou seja, em 2011, apenas 2,3\% de todos os museus (na Lei Rouanet de 2003 a 2010) estão com prestação de contas aprovada. Em média, apenas a metade dos beneficiados apresentou prestação de contas, e a maioria dessas encontra-se em análise (Quadro 5).

Considerando o universo dos que apresentaram prestação de contas (aprovada ou em análise), mais da metade já as apresentou. Para 2008, esse percentual é baixo (35\%), e para 2009 e 2010, é respectivamente de $8 \%$ e $0 \%$ (Quadro 5). É mais provável que esse baixo percentual se deva a problemas informacionais - ao fato de o projeto haver apresentado as informações, mas estas não constar no sistema -, do que a problemas de execução dos projetos. 
Quadro 5: Museus ou projetos culturais da área museológica, apresentados no MinC de 2003 a 2010, que tiveram por foco o incentivo fiscal

\begin{tabular}{|l|l|l|l|l|l|l|l|r|r|}
\hline Ano & $\mathbf{2 0 0 3}$ & $\mathbf{2 0 0 4}$ & $\mathbf{2 0 0 5}$ & $\mathbf{2 0 0 6}$ & $\mathbf{2 0 0 7}$ & $\mathbf{2 0 0 8}$ & $\mathbf{2 0 0 9}$ & $\mathbf{2 0 1 0}$ & TOTAL \\
\hline Quantidade de projetos & 24 & 40 & 61 & 56 & 34 & 17 & 12 & 18 & $\mathbf{2 6 2}$ \\
\hline Situação & & & & & & & & & \\
\hline B14 Diligenciado - Parecer técnico & 0 & 0 & 1 & 0 & 0 & 0 & 0 & 0 & 1 \\
\hline C08 Análise técnica concluída & 0 & 1 & 4 & 7 & 0 & 0 & 0 & 0 & 12 \\
\hline $\begin{array}{l}\text { C13 Projeto incluído na pauta de } \\
\text { complementação para avaliação da CNIC }\end{array}$ & 0 & 0 & 0 & 0 & 0 & 0 & 0 & 1 & 1 \\
\hline $\begin{array}{l}\text { E12 Autorizada a captação residual } \\
\text { dos recursos }\end{array}$ & 1 & 0 & 2 & 12 & 6 & 10 & 9 & 16 & 56 \\
\hline $\begin{array}{l}\text { E13 Projeto em execução. Encerrado prazo } \\
\text { de captação. }\end{array}$ & 0 & 1 & 0 & 1 & 1 & 1 & 1 & 1 & 6 \\
\hline E15 Expirado o prazo de captação parcial & 0 & 2 & 6 & 2 & 4 & 0 & 1 & 0 & 15 \\
\hline E18 Avaliação técnica do relatório final & 0 & 2 & 3 & 2 & 2 & 0 & 0 & 0 & 9 \\
\hline E19 - Prestação de Contas aprovada & 1 & 3 & 2 & 0 & 0 & 0 & 0 & 0 & 6 \\
\hline $\begin{array}{l}\text { E20 Inadimplente - não respondeu à } \\
\text { diligência da prestação de contas }\end{array}$ & 2 & 2 & 3 & 1 & 0 & 0 & 0 & 0 & 8 \\
\hline E22 Instaurada tomada de conta especial & 1 & 0 & 0 & 0 & 0 & 0 & 0 & 0 & 1 \\
\hline E23 Inadimplente & 1 & 1 & 1 & 4 & 3 & 0 & 0 & 0 & 10 \\
\hline E24 Apresentou prestação de contas & 16 & 24 & 32 & 24 & 16 & 6 & 1 & 0 & 119 \\
\hline $\begin{array}{l}\text { E27 Análise financeira da prestação de } \\
\text { Contas }\end{array}$ & 2 & 4 & 2 & 1 & 1 & 0 & 0 & 0 & 10 \\
\hline E30 Análise de resposta de diligência & 0 & 0 & 2 & 2 & 0 & 0 & 0 & 0 & 4 \\
\hline G08 Visto da consultoria jurídica & 0 & 0 & 0 & 0 & 1 & 0 & 0 & 0 & 1 \\
\hline L07 Recolhimento integral dos recursos & 0 & 0 & 3 & 0 & 0 & 0 & 0 & 0 & 3 \\
\hline $\begin{array}{l}\text { \% dos que apresentaram prestação de } \\
\text { contas (E18+ E19 + E24 + E27 + E30) }\end{array}$ & $79 \%$ & $83 \%$ & $67 \%$ & $52 \%$ & $56 \%$ & $35 \%$ & $8 \%$ & $0 \%$ & \\
\hline \% de inadimplentes (E 20 + E 22 + E 23) & $17 \%$ & $8 \%$ & $7 \%$ & $9 \%$ & $9 \%$ & $0 \%$ & $0 \%$ & $0 \%$ & \\
\hline \begin{tabular}{l} 
\% com prestação de contas aprovada \\
\hline
\end{tabular} & $4,2 \%$ & $7,5 \%$ & $3,3 \%$ & $0,0 \%$ & $0,0 \%$ & $0,0 \%$ & $0,0 \%$ & $0,0 \%$ & \\
\hline
\end{tabular}

Fonte: Elaboração própria a partir de relatórios fornecidos pelo MinC e pelo Iphan em julho e agosto de 2011

Mas há de se investigar com mais detalhes, projeto a projeto, para confirmar essa suposição. Caso o problema seja na execução do projeto, há de se buscar outras soluções, que não a melhora no fluxo de informações.

Do ponto de vista dos proponentes, aparentemente a prestação de contas não é vista como problemática. Nas entrevistas, alega-se que tudo foi feito com tranquilidade, manifestando a não compreensão do porquê da demora para aprovar as contas.

- "A prestação de contas não deu trabalho nenhum".

- "A prestação de contas é tranquila. Se você anda na linha, a prestação de contas vem automaticamente. É claro que vem burocracia, mas a burocracia é necessária para o controle do projeto, não é empecilho nenhum".

- "Não há nenhuma dificuldade. Agora, o jeitinho brasileiro é que complica a prestação de contas. A partir do momento que eu tenho tudo em ordem eu consigo fazer essa prestação."

- "Nós temos aqui um checklist, e sabemos que tem de apresentar notas, fazer os cruzamentos, ter os controles dos cheques nos bancos; então, a gente faz tudo certinho. A gente não paga nada sem nota, se informa se tem problema na nota, só compra de quem tem nota, pesquisa as notas para ver se são viáveis ou não. A 
gente tem que tomar todo o cuidado possível durante, para não ter problema depois. E não temos problema para prestar contas, não."

- "A prestação de contas da Rouanet nós apresentamos também aos patrocinadores, porque a prestação de contas da Rouanet é tão detalhada, é bem detalhadinho, tudo, então é a mesma para todos. Agora, em relação ao relacionamento com o Ministério da Cultura, foi tudo super tranquilo. Vem tudo muito detalhado. Prestar contas é tranquilo".

- "Eles têm as normas ali. A partir do momento que você conhece aquelas normas, dá tudo certinho. Você preenche lá as planilhas, apresenta a documentação toda direitinha, não dá trabalho. Apresenta as certidões. $\mathrm{O}$ instituto, a organização, não te dá trabalho. Acompanha direitinho mês a mês, acompanha as certidões; se uma vai vencer, ele já corre atrás. Funciona muito bem."

- "A prestação de contas foi toda dentro do previsto".

Mas há críticas também:

- "Eu acho que o grande problema hoje no ministério é que eles têm uma equipe pequena e isso acarreta um monte de coisas, e tinham que colocar na equipe de prestação de contas gente com bom-senso, que tivesse um ponto de vista melhor. Isso, das notas, é difícil."

Afirmaram que mantêm toda a documentação guardada, "em caixas e mais caixas", caso haja alguma auditoria, já que conseguem visualizar no sistema que suas contas não foram aprovadas ainda. Um proponente afirmou em uma das entrevistas: "Estou aguardando aí. A gente está sempre na corda-bamba com o MinC". Outra curiosidade, que decorre da análise das entrevistas, é que todos alegam que não há problemas informacionais no que diz respeito às informações que o proponente deve passar ao governo, mas sim no sentido inverso: das informações que o governo deve passar aos proponentes. Os proponentes se queixam de que não têm informações sobre a análise de projeto, sobre a existência de empresas financiadoras, sobre editais de estatais, mas principalmente sobre o andamento da prestação de contas.

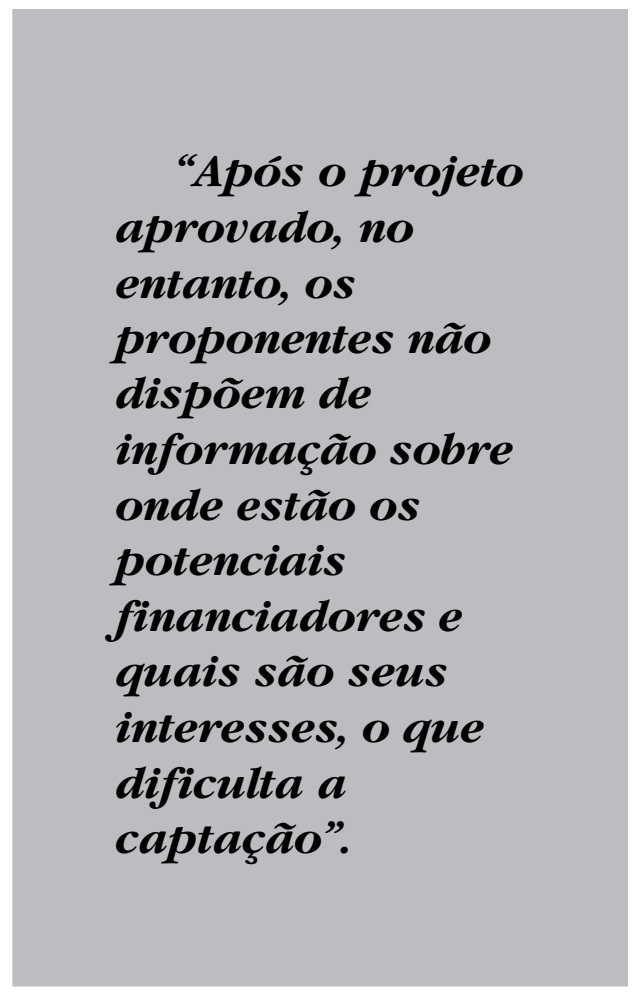

De qualquer forma, a partir de todos esses pontos de vista, há indicativos, conforme exposto aqui, de que problemas informacionais têm impedido a boa implementação via incentivo fiscal.

Etapas e Tempo. Referências a etapas e tempo são as mais frequentes no conjunto das entrevistas.

Pela análise documental, constata-se que há oito etapas. Os interessados inscrevem projetos junto ao MinC, que os analisa preliminarmente e os encaminha à Comissão 
Nacional de Incentivo à Cultura (CNIC), que emite o parecer; posteriormente o $\mathrm{MinC}$ publica o resultado final. O tempo médio entre o cadastramento de usuário (primeira etapa) e o resultado final é de oito meses, chegando a demorar até um ano (BRANT, 2009), mas, por vezes, demorando apenas três meses (conforme entrevistas). Foi identificada certa dificuldade para inscrição de um projeto, devido aos critérios, obrigações e exigências da lei (SiLva, Midlej, 2011). A estimativa desconsidera o tempo que se leva para inscrever um projeto e considera o tempo decorrido a partir do projeto inscrito.

Existem problemas administrativos referentes ao CNIC, pois há cerca de doze mil projetos por ano para serem examinados por uma comissão constituída por vinte pessoas aproximadamente, que são pareceristas voluntários (Silva, MidleJ, 2011). Para a etapa seguinte, não há dados suficientes para se estimar o tempo médio entre o resultado final (com base no parecer do CNIC) e a captação, para enfim chegarmos à execução do projeto. Com base nas entrevistas, estima-se que leva em média um ano - prazo máximo para captação -, sendo que por vezes é preciso que os proponentes solicitem prorrogação do prazo para viabilizar a captação.

Depois de aprovado, cada projeto tinha, conforme o regulamento (no período analisado), um prazo máximo de dois anos para conseguir a captação. Caso não conseguisse captação em até dois anos, o projeto era arquivado. Supõe-se, assim, haver internamente estimativas no Ministério de que o tempo para captação não deve exceder dois anos. Após a captação, haveria prazo de um ano para a implementação. Somando todos esses prazos, temos um tempo médio de implementação de quatro anos.
Pelo Quadro 5, observamos que, em agosto de 2007, só há projetos com prestação de contas aprovada referentes aos anos 2003, 2004 e 2005, ou seja, aprovados há mais de cinco anos. Quanto à prestação de contas, há percentuais mais elevados para o período de 2003 a 2007, caindo consideravelmente em 2008, 2009 e 2010, o que permite concluir que isso se deve ao fato de o ciclo de quatro anos ainda não ter se completado.

Os entrevistados afirmam que o processo "demora muito tempo", "que é muito demorado", que "demora mais do que você imagina". Por vezes alegam que houve greve no MinC, que não sabem por que demora tanto. Concordam que "tem que ficar em cima". Há relatos pontuais de atrasos específicos, devido a ajustes nos projetos ou mesmo devido à demora que acarreta ajustes nos projetos (preços defasados que devem ser negociados ou devese buscar alternativas quando finalmente o projeto começa a ser implementado). De qualquer forma, o tempo é longo e desanima os que se utilizam da Lei Rouanet. E a demora é geralmente associada a problemas informacionais: "tudo é bem difícil". Mas concordam que melhorou muito com o SalicWeb, com a informatização do processo.

Apoio Institucional. Revelou-se, por meio das entrevistas, como contrapeso à autonomia. Nos casos de pessoa física (proponente), isso ficou bastante evidenciado. O proponente tem total autonomia, mas não tem apoio nenhum e necessita deste para manutenção do museu. Sem apoio institucional (seja de governos subnacionais, de empresas ou instituições) o processo fica desgastante, precário e suscetível a descontinuidades.

Nas palavras dos proponentes entrevistados, quando inquiridos acerca do 
processo de elaboração, aprovação e implementação do projeto: "É um horror! É muito difícil! É muito complicado!”, “É muito difícil. Muito complicado", "A experiência foi muito amarga, foi muito difícil, uma trabalheira danada", "Tudo foi bem difícil". O apoio institucional não tem relação com afinidade partidária, mas sim com sensibilizar a instituição, normalmente a prefeitura (também a empresa privada), da necessidade de apoiar aquele projeto, para que sua manutenção seja possível. Ele é necessário ainda que a renúncia fiscal seja apoiada em mecanismo de mercado.

Os entrevistados inclusive afirmam que ser proponente (pessoa física) é difícil, que dificulta a captação (não só a implementação), e que o próprio MinC tem incentivado que os proponentes sejam todos pessoa jurídica, para poder contar com maior apoio institucional ou, ao menos, maior experiência. Há relatos inclusive que atestam: "eu já tinha a préaprovação, mas, como eu era pessoa física, não me aprovaram”. E a importância do apoio institucional também se evidencia na afirmação de um dos entrevistados sobre o MinC e todo o processo:

- "Facilita conhecer uma pessoa lá."

- "É complicado porque eu vejo hoje né, o patrocínio no Brasil ainda é muito político. Depende muito de relacionamento político, relacionamento direto às vezes com pessoas importantes da empresa, isso tem um peso muito grande no papel da pessoa que capta."

- "Não que a empresa vá patrocinar algo que não tenha a ver com ela, mas dentre vários que tem a ver com ela, ela acaba optando por aquele projeto que chegou ali através de um relacionamento político, um apelo político, ou um relacionamento forte com uma pessoa importante e tal."
- "Então acaba que o relacionamento, a pessoa conhecer, estar na área há muito tempo, ter uma costa quente, ou um respaldo já, ainda ajuda. Ajuda bastante."

$\mathrm{O}$ apoio institucional se manifesta, portanto, como apoio do prefeito para manutenção do museu (depois que o projeto é implementado com recursos da Rouanet), apoio para aprovação do projeto dentro do MinC e apoio para seleção do projeto pela empresa financiadora.

Apoio Social. O apoio social teve pouco peso ao longo das entrevistas. $\mathrm{O}$ que se pode considerar aqui são menções no contexto das perguntas sobre quem frequenta o museu. Contrário ao que seria esperado, os entrevistados afirmaram que a implementação do projeto que conseguiu captação da Lei Rouanet "não teve impacto na visitação”. Em alguns casos, expressaram desapontamento pelo fato de o museu ter sido construído (e ser mantido) com objetivo de atender a comunidade, mas atualmente ser procurado majoritariamente por estudantes de mestrado, doutorado e pesquisadores em geral, em vez de usado pela comunidade. Para buscar maior envolvimento, tentam, em iniciativas pontuais e escassas, fazer contato com escolas públicas das localidades, para que essas visitem os museus. Têm funcionado, mas não de forma institucionalizada.

Nas entrevistas, a palavra "social" apareceu em três trechos: "o projeto tem de ter um apelo social bom para iniciar qualquer conversa para futura captação" (mas isso foi classificado como incentivos, visto que estávamos tratando de captação); "o que caracteriza o apelo social é geralmente a distribuição gratuita"; e "o apelo social é mediante disponibilização na internet". Nenhuma dessas citações se refere propriamente ao público, mas sim ao 
processo de captação, ou a como fazer um projeto ser atraente ao potencial patrocinador ou ter sucesso ao concorrer aos editais da Petrobrás ou de outras estatais.

Quando inquiridos explicitamente sobre o público e a mobilização social, mencionam:

- “Os que moram lá vão uma vez e não voltam mais, né. Mas tem turista."

- "As escolas são o nosso maior público. A gente atende as escolas. A gente tem contato com as escolas durante o ano inteiro. É o nosso forte. É o forte do nosso público."

- "Agora, mobilização da sociedade para apoiar o museu... isso é uma discussão que a gente tem aqui. Eu não sei. A gente tem de semear mesmo. É uma coisa de começar um trabalho mesmo de conscientização, para ir colher os frutos aos poucos."

Dos relatos, depreende-se que inserir um projeto para aprovação e futura captação e implementação pela Lei Rouanet é, às vezes, uma iniciativa pessoal, individual, conforme história de vida do proponente/pessoa física ou de algum funcionário do proponente/ pessoa jurídica. $\mathrm{O}$ apoio para a criação do museu não vem de uma exigência da sociedade. Assim, o apoio social, em todos os seus aspectos, mostrou-se fraco.

\section{Conclusões e recomendações}

A partir do exposto, as principais conclusões são as seguintes:

O incentivo financeiro é a grande força motriz da Lei Rouanet. Até o próprio MinC a utiliza para aumentar seus recursos por outras vias que não orçamentárias. No entanto, a renúncia fiscal é concentradora, desigual e apresenta baixa participação das empresas.

A renúncia permite considerável autonomia. No entanto, contrariamente ao indicado pela revisão de literatura, chegou-se à conclusão de que a autonomia nem sempre é vista como positiva pelos implementadores, por ter como contrapeso falta de apoio institucional.

Os problemas informacionais fazem surgir distorções, tais como 'intermediários', 'mercado paralelo' de informações e problemas gerenciais. Além disso, problemas informacionais estão relacionados a problemas de gestão e, também, da quantidade de etapas e do tempo decorrido entre cada etapa do processo de implementação.

A quantidade de etapas e o tempo necessário para completar todo o processo é uma variável que prejudica seu bom funcionamento, pois há muitas etapas e prazos longos, ocasionando demora entre cada etapa e demora para implementação. Essas questões estão intimamente relacionadas com questões informacionais e também com apoio institucional.

O apoio institucional é uma variável importante e que insere instabilidade, devido à necessidade que os proponentes têm de terem tal apoio para manutenção de cada museu. Ficou evidenciado, ainda, que o museu implantado pelo mecanismo de renúncia fiscal necessita de apoio institucional para sua manutenção.

Quanto ao apoio social, parece ser de pouca importância para o uso da renúncia fiscal. O apoio social interessa, mas é ainda muito incipiente, no sentido de que o museu não pode contar com a sensibilização da sociedade ou com o apoio da comunidade para sua existência e manutenção. Cada museu ainda considera como tarefa necessária, a qual deve partir de sua própria iniciativa, provocar e construir esse apoio junto com a comunidade.

Em suma, apesar de haver incentivos e autonomia em grau suficiente para, conforme a literatura pertinente, possibilitar 
o bom uso da renúncia fiscal na área de museus, há problemas informacionais que dificultam essa implementação. Há também barreiras referentes ao apoio institucional e às etapas e tempo. Ambos parecem limitar os efeitos da implementação de museus mediante o uso da Lei Rouanet.

As contribuições deste artigo se devem ao fato de ter ouvido proponentes de projetos museológicos implementados mediante o uso da renúncia fiscal e de fazer um levantamento do seu uso na área de museus, o que pode expor ao governo problemas na implementação que talvez possam ser contornados.

As recomendações de cunho teórico, que convém mencionar, se atêm à necessi- dade de analisar outros instrumentos governamentais que estão em uso para implementação de museus e de comparar tais instrumentos com a análise desenvolvida neste trabalho, para constatar se haveria um instrumento ou um mix de instrumentos mais adequados para a área de museus. Também seria conveniente (uma recomendação prática) propor ao Ibram e ao MinC que façam um "pente fino" nas prestações de contas e contatem proponentes para que tomem conhecimento dos problemas enfrentados e possam propor novas mudanças.

(Artigo recebido em novembro de 2011. Versão final em dezembro de 2011).

\section{Notas}

${ }^{*}$ Este artigo partiu da fase inicial de pesquisa de doutorado que compara a implementação da Política Nacional de Museus mediante o uso de renúncia fiscal, assistência financeira e gestão direta. A tese é bem mais abrangente que este artigo, chega a conclusões interessantes e está à disposição de interessados (contatar autoras).

${ }^{1}$ Pressupõe-se que proponentes são implementadores "na ponta", conforme teorias de implementação "bottom-up" (HILL, HUPE, 2002). Além disso, este artigo é parte de uma pesquisa que entrevistou 28 implementadores, incluindo governo federal, diretores de museus e outros que implementam a Política Nacional de Museus mediante o uso de outros instrumentos governamentais, tais como assistência financeira e gestão direta.

${ }^{2}$ Problemas de classificação dentro do sistema de controle da Lei Rouanet foram identificados e confirmados em entrevistas com atuais e antigos servidores do Ibram. Essas e as entrevistas com os proponentes foram gravadas e estão à disposição dos interessados. Não se tem a mensuração das classificações duplicadas ou erradas, mas sabe-se que há indícios de classificação dúbia ou errada, apurados em casos isolados. O SalicNet está disponível na internet e, para fins de consulta, seu acesso é público, dispensando uso de senhas.

${ }^{3}$ A identidade (bem como o cargo) foi preservada a pedido dos entrevistados. As entrevistas foram gravadas e estão disponíveis (contatar autoras).

${ }^{4}$ As áreas são: artes cênicas, artes integradas, artes visuais, áudio visual, humanidades, música e patrimônio cultural. 


\section{Referências bibliográficas}

Brant, Leonardo. O poder da cultura. Editora Peirópolis, 2009.

BrasiL. Cultura em números: anuário de estatísticas culturais 2009. Brasília: MinC, 2009. . Lei $\mathrm{n}^{\circ}$ 8.313, de 23 de dezembro de 1991. Restabelece princípios da Lei $\mathrm{n}^{\circ}$ 7.505, de 2 de julho de 1986, institui o Programa Nacional de Apoio à Cultura (Pronac) e dá outras providências. Diário Oficial da União. Brasília, DF, nº 249, p. 9-12, 24 dez. 1991. Seção 1.

. Política Nacional de Museus. Relatório de Gestão 2003/2010. Ministério da Cultura - MinC, Instituto Brasileiro de Museus - IBRAM, Brasília-DF, 2010.

. Políticas sociais "acompanhamento e análise. Ministério do Planejamento, Orçamento e Gestão, Instituto de Pesquisa Econômica Aplicada - IPEA, no 16, nov. 2008, p. 132-133, 2008.

Coase, R. H. The nature of the firm. Economica, New Series, vol. 4, n 16, Nov., 1937, p. 386-405.

Fox, Charles J. Implementation research: why and how to transcend positivist methodologies. In: Palumbo, Dennis J.; Calista, Donald J. (orgs). Implementation and the policy process: opening up the black box. Greenwood Press, USA, 1990. Capítulo 13, p. 199-212.

Hill, M.; Hupe, P. Implementing public policy. London: Sage Publications Ltd., 2002.

Hoon, Christopher. The tools of government. Chatham, NJ: Chatham House Editores, 1986. Huque, Ahmed Shafiqul. Does Ideology Matter? Incentive, Efficiency and Management in the Public Sector. International Journal of Public Administration, v. 32, nº 11, p. 929 - 950, 2009.

Kraft, Michael E.; Furlong, Scott R. Public Policy: politics, analysis, and alternatives. Washington-DC, EUA: CQPress, 2007.

LANE, Jan-Erik. Public Administration and Public Management. the principal-agent perspective. Routledge Editora, 2005.

Miles, M: Huberman, M. Qualitative Data Analysis. Sage Publications, 1994.

Mousinho, Clara. Fraude em benefícios da Lei Rouanet começou em 2004, informa Polícia Federal. Matéria jornalística da Agência Brasil. Disponível em: http://agenciabrasil.ebc.com.br/ noticia/2007-11-07/ fraude-em-beneficios-da-lei-rouanet-comecou-em-2004-informapolicia-federal. Acesso em: out. 2011.

Noblat, Ricardo. Ministro da Cultura admite falha no combate a fraudes. Blog jornalístico. Disponível em: http://oglobo.globo.com/pais/noblat/?palavra=rouanet. Acesso em: out. 2011. Peters, Guy. Policy instruments and public management: bridging the gaps. Journal of public administration research and theory, v. 10, n 1, p. 35-47, jan. 2000.

Pressman, J. L.; Wildavsky, A. Implementation. Berkeley: University of California Press, 1973. SALAmON, L. The tools of government: a guide to the new governance. Oxford. 2002.

SILVA, Frederico A. Barbosa da. Economia e política cultural: acesso, emprego e financiamento. Coleção Cadernos de Políticas Culturais. Ministério da Cultura, Instituto de Pesquisa Econômica Aplicada - IPEA. Volume Três. Brasília. 2007a. 
SiLva, Frederico A. Barbosa da. Política cultural no Brasil 2002-2006: acompanhamento e análise. Coleção Cadernos de Políticas Culturais, v. 2. Ministério da Cultura, Instituto de Pesquisa Econômica Aplicada - IPEA, Brasília, 2007b.

Silva, Frederico A. Barbosa da; Midlej, Suylan. Politicas Públicas Culturais - a voz dos gestores. Brasília: IPEA, 2011.

Silva, Frederico Barbosa da; Jaccoud, Luciana; Beghin, Nathalie. Políticas sociais no Brasil: participação social, conselhos e parcerias. In: JACCOUD, Luciana (org). Questão social e políticas sociais no Brasil contemporâneo. Ipea, Brasília, 2005. Cap. 8, p. 373-407. 435p. STiglitz, Joseph E. Economics of the Public Sector. W.W. Norton Editora, 1988.

Williamson, Oliver E. Transaction Cost Economics: An Introduction. Disponível em: www.economics-ejournal.org/economics/discussionpapers Acesso em: out. 2011.

YIN, Robert K. Case Study Research: design and methods. Third Edition. Sage Publications, 2003. 


\section{Resumo - Resumen - Abstract}

\section{O uso da renúncia fiscal na área de museus}

Janann Joslin Medeiros e Leila Giandoni Ollaik.

O objetivo desse artigo é investigar como a renúncia fiscal é utilizada na área de museus. A fundamentação teórica faz breve apresentação da literatura sobre implementação e descreve o uso da renúncia fiscal na área de museus mediante análise de seis variáveis: incentivos, autonomia, informação, apoio institucional, apoio social e etapas e tempo. A metodologia utilizada foi a análise documental e entrevistas. A análise foi feita com ajuda do programa NVIVO9. As principais conclusões são que embora haja incentivos e autonomia em graus suficientes para permitir boa implementação via renúncia fiscal, há questões informacionais e referentes às etapas e tempo que dificultam sua implementação. Além disso, a renúncia fiscal é concentradora, desigual e apresenta baixa participação de empresas do setor privado. Esses problemas parecem diminuir a capacidade de a implementação de museus mediante o uso da renúncia fiscal alcançar os efeitos almejados.

Palavras-chave: implementação de política pública, renúncia fiscal, museus.

\section{E1 uso de exenciones fiscales para Museos}

Janann Joslin Medeiros y Leila Giandoni Ollaik.

El objetivo es describir el uso de la exención fiscal por museos. La fundamentación teórica trata de implementación en general y más específicamente de la exención fiscal, con análisis de seis variables: incentivos, autonomía, información, pasos/tiempo, apoyo institucional y apoyo social. Para la metodología, fueron utilizados análisis documental y entrevistas. El análisis fue realizado con la ayuda del programa NVIVO9. Las principales conclusiones son las de que, aunque existan incentivos y autonomía en grado suficiente para permitir la implementación via exenciones fiscales, existen problemas de información y pasos/tiempo que disminuyen su capacidad. Además, la excención fiscal es concentradora, desigual y con baja participación de las empresas. Estos problemas parecen haber contribuido para impedir que la implementación de museos a través del uso de excención fiscal haya tenido los efectos deseados.

Palabras clave: implementación de políticas públicas, exenciones fiscales, museos.

\section{The use of fiscal incentives by museums \\ Janann Joslin Medeiros and Leila Giandoni Ollaik.}

This paper investigates how tax exemptions have been used by museums. It describes the use of tax exemptions in terms of six key variables: incentives, autonomy, information, institutional support, social support and timeframe. The theoretical foundation presents a summary of the literature on implementation, conceptualizing the variables to be used in the analysis. Data were collected by means of analysis of governmental documents and interviews with proponents who implemented museums financed via tax exemptions. Data analysis was supported by the use of NVIVO9 software. Findings reveal that although the levels of incentives and autonomy appear adequate to the implementation via tax exemptions; information problems and barriers related to the number of steps and the amount of time needed to implement each project appear to have severely limited its potential to foster museums implementation.

Keywords: public policy implementation, tax exemptions, fiscal incentives, museums. 
Janann Joslin Medeiros

Doutora em Administração Pública pela University of Southern California, mestre em Administração Pública pela George Washington University e bacharel em Ciência Política pela University of Iowa. Atualmente é professora adjunta da Universidade de Brasília e líder do grupo de pesquisa em relações interorganizacionais e redes. Contato: janmedeiros@gmail.com

Leila Giandoni Ollaik

Doutoranda em Administração Pública pela Universidade de Brasília (UnB), mestre em Políticas Públicas (MSc in Public Policy in Latin America) pela Universidade de Oxford, mestre em Ciência Política pela Universidade de Brasília (UnB) e bacharel em Economia pela Universidade de Brasília (UnB). É Especialista em Políticas Públicas e Gestão Governamental - EPPGG, carreira do Ministério do Planejamento, Orçamento e Gestão, desde 1997. Contato: leila.ollaik@gmail.com 